\title{
Endovascular embolization in renal trauma: a narrative review
}

\author{
Tyler Andrew Smith ${ }^{1}$, Adriene Eastaway², Duncan Hartt ${ }^{2}$, Keith Bertram Quencer ${ }^{1}$ \\ ${ }^{1}$ Department of Interventional Radiology, ${ }^{2}$ Department of Radiology and Imaging Sciences, University of Utah, Salt Lake City, UT, USA \\ Contributions: (I) Conception and design: All Authors; (II) Administrative support: KB Quencer; (III) Provision of study materials or patients: \\ TA Smith, A Eastaway, KB Quencer; (IV) Collection and assembly of data: All Authors; (V) Data analysis and interpretation: All Authors; (VI) \\ Manuscript writing: All authors; (VII) Final approval of manuscript: All authors. \\ Correspondence to: Tyler Andrew Smith. Department of Interventional Radiology, University of Utah, 30 N 1900 E, Salt Lake City, UT 84132 , USA. \\ Email: Tyler.a.smith@hsc.utah.edu.
}

\begin{abstract}
Approximately 1-3\% of all trauma patients have a renal injury. Eighty percent of renal trauma is due to blunt injury, with the remainder due to penetrating trauma which is most often iatrogenic. Contrast enhanced computed tomography is used to triage patients and offers a quick and accurate assessment of any potential organ injury. If injury is present, The American Association for the Surgery of Trauma grading system can both grade renal injuries and be used to help guide management and intervention. Grades are assigned based on imaging and clinical features of renal trauma, and have prognostic and treatment implications for patients. The objective of this narrative review is to identify optimal management of patients with renal trauma, specifically which patients can be treated with endovascular interventions following renal trauma, which can be observed, and which would be best managed surgically. For hemodynamically stable patients with renal trauma, endovascular angiography and embolization is a non-invasive approach that can be used to control bleeding and potentially avoid surgery or nephrectomy in select cases. Future research is needed to determine if a specific antibiotic regimen is needed prior to or following embolization. Further research is needed to evaluate the effectiveness of endovascular management of high-grade renal trauma (grade V). Complications of renal embolization include short-term hypertension, long term hypertension in cases of significant ischemia, acute kidney injury, and infection.
\end{abstract}

Keywords: Renal trauma; renal artery embolization; shattered kidney; renal angiography

Submitted May 28, 2020. Accepted for publication Jul 19, 2020.

doi: $10.21037 /$ atm-20-4310

View this article at: http://dx.doi.org/10.21037/atm-20-4310

\section{Introduction}

Approximately $1-3 \%$ of all trauma patients have renal injury $(1,2)$. Eighty percent of renal trauma is due to blunt injury (1). Penetrating trauma is often iatrogenic (i.e., renal biopsy, partial nephrectomy, tumor ablation, and nephrostomy placement) but can be due to a gunshot wound or stabbing (3). After the spleen and liver, the kidney is the third most common intra-abdominal organ injured in the setting of trauma (4). While the majority of renal traumas can be managed conservatively, about $10 \%$ require embolization and $5 \%$ require nephrectomy (3). The purpose of this narrative review is to discuss the imaging findings of renal trauma, triage, treatment, and outcomes with a focus on endovascular interventions.

We present the following article in accordance with the Narrative Review reporting checklist (available at http:// dx.doi.org/10.21037/atm-20-4310).

\section{Methods}

A literature search was conducted using PubMed (US National Library of Medicine, Bethesda, MD). No studies were excluded based on year of publication. Studies which investigated the imaging findings and management of renal

$\wedge$ ORCID: 0000-0002-1759-1711. 
trauma were included, with an emphasis on endovascular management. Search terms included: renal embolization, renal trauma, renal angiography, blunt abdominal trauma.

\section{Imaging}

Although hematuria is the most common sign of renal trauma, it may be absent, even in cases involving significant injury (5). Therefore imaging, specifically with contrast enhanced computed tomography (CT) is of paramount importance in the initial evaluation and triage of trauma patients with suspected renal injury and should be performed in all hemodynamically stable trauma patients. To accurately grade renal injuries, the CT protocol should include the full abdomen and pelvis with late-arterial or portal-venous phase (50-70 seconds after contrast injection).
If renal injury is present on initial scans or there is clinical suspicion for injury to the collecting system, a urographicphase CT (4-5 minutes after contrast injection) should be obtained to evaluate for urine leak (6-9).

\section{Grading}

The American Association for the Surgery of Trauma (AAST) CT grading system helps triage patients appropriately (10-12) (Table 1). The AAST Kidney Injury Scale ranges from mild (grade I) to severe (grade V). Grading is based primarily on the size of laceration(s) and the proximity to the renal hilum (11). Current AAST grading system does not account for active contrast extravasation from an injured blood vessel.

The World Society of Emergency Surgery (WSES) has

Table 1 Adaptation of the AAST renal injury grading system, with an emphasis on CT findings. Prior studies have reported that approximately $28-32 \%$ of renal injuries are grade I, $16-26 \%$ grade II, $19-22 \%$ grade III, $18-25 \%$ grade IV, and $4-9 \%$ grade V $(2,12)$

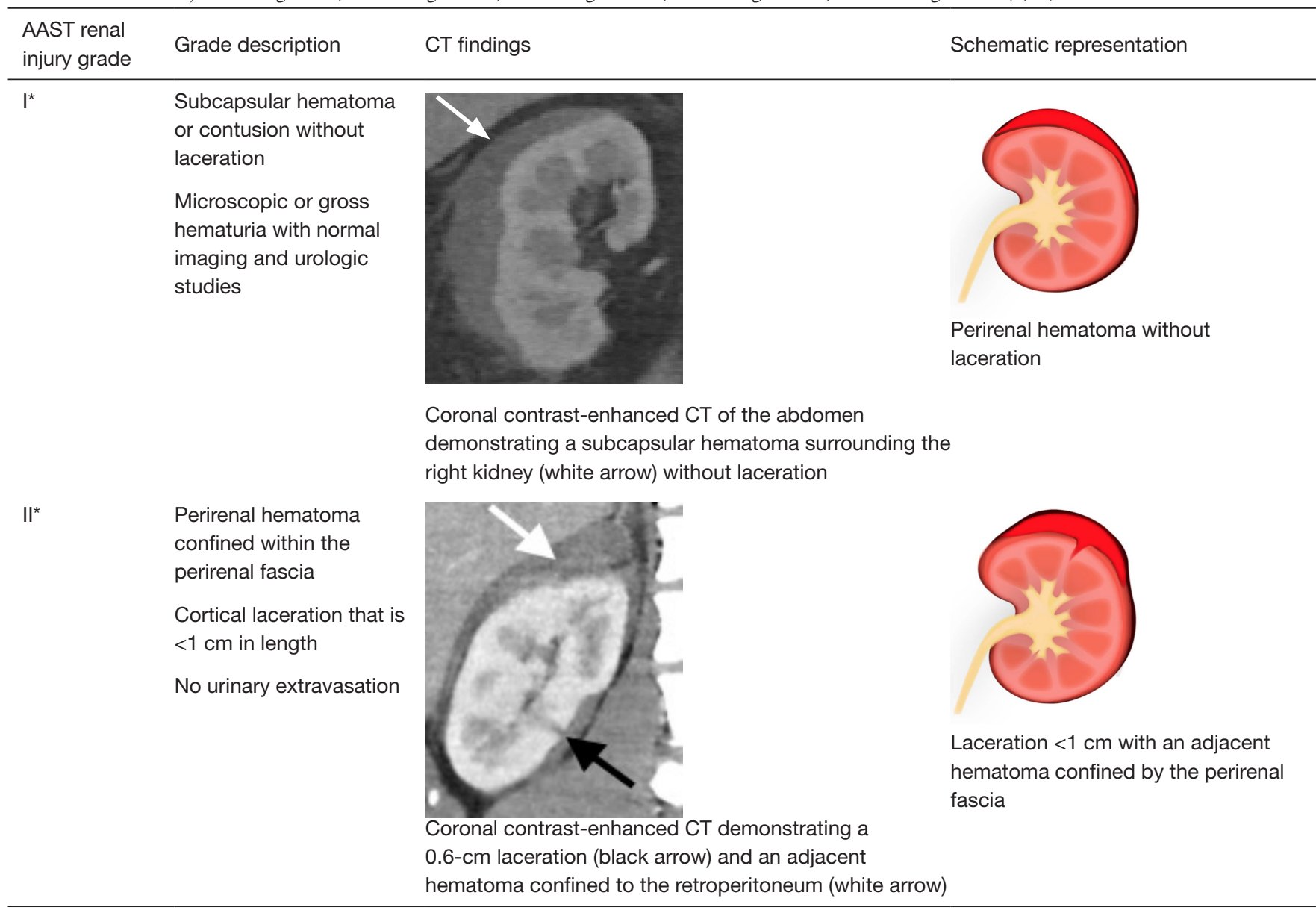

Table 1 (continued) 
Table 1 (continued)

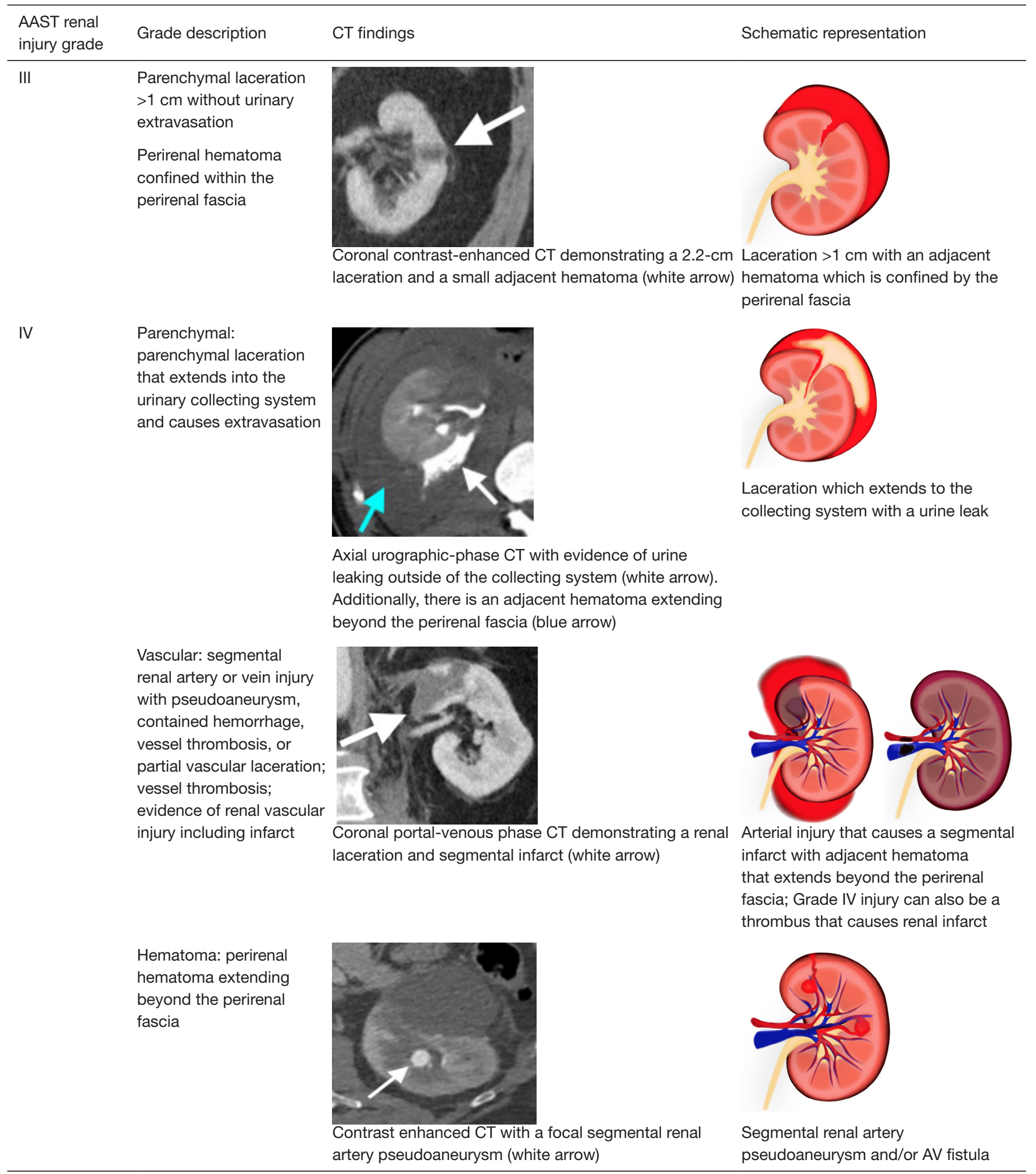

Table 1 (continued) 
Table 1 (continued)

\begin{tabular}{|c|c|c|c|}
\hline $\begin{array}{l}\text { AAST renal } \\
\text { injury grade }\end{array}$ & Grade description & CT findings & Schematic representation \\
\hline \multirow[t]{4}{*}{ V } & $\begin{array}{l}\text { Parenchymal: shattered } \\
\text { kidney }\end{array}$ & 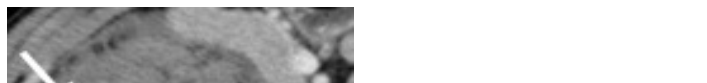 & \\
\hline & & $\begin{array}{l}\text { Axial CT demonstrating a shattered kidney (white arrow) } \\
\text { with an adjacent hematoma extending beyond the } \\
\text { perirenal fascia (black arrow) }\end{array}$ & \\
\hline & $\begin{array}{l}\text { Vascular: main renal arter } \\
\text { or vein with complete } \\
\text { laceration or avulsion; } \\
\text { devascularization of the } \\
\text { kidney }\end{array}$ & & 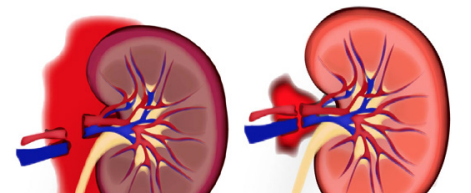 \\
\hline & & $\begin{array}{l}\text { Contrast enhanced CT with injury to the renal vascular } \\
\text { pedicle (white arrow) causing near complete infarct of } \\
\text { the renal parenchyma (blue arrows) }\end{array}$ & \\
\hline
\end{tabular}

*, advance by one grade for bilateral injuries up to grade III. CT, computed tomography; AAST, the American Association for the Surgery of Trauma.

Table 2 Adaptation of the WSES grading system. This system considers both the AAST grade and hemodynamic stability, with unstable patients with any grade of injury being classified as WSES grade $I V$

\begin{tabular}{lcc}
\hline WSES grade & AAST & $\begin{array}{c}\text { Hemodynamic } \\
\text { stability }\end{array}$ \\
\hline Minor (grade I) & I-II & Stable \\
Moderate (grade II) & III or segmental vascular & Stable \\
& injury &
\end{tabular}

Severe

Grade III $\quad \begin{gathered}\text { IV-V or parenchymal } \\ \text { lesion with main vessel } \\ \text { dissection/occlusion }\end{gathered}$

Grade IV I-V Unstable

AAST, the American Association for the Surgery of Trauma; WSES, the World Society of Emergency Surgery. an additional classification system which considers both the AAST classification and the patient's clinical status (Table 2).

\section{Triage}

The AAST renal injury grading can help triage patients for appropriate management. AAST grade I and II injuries are generally self-limited without long term sequela and can be observed $(6,11)$. Patients are at risk for nonoperative management failure when CT demonstrates active contrast extravasation from an injured blood vessel $(6,13,14)$. Therefore, strong consideration should be given to endovascular embolization in patients whose imaging demonstrates vascular contrast extravasation even if the AAST grade is low. Hemodynamically stable patients with grade III and IV vascular injuries should be treated 

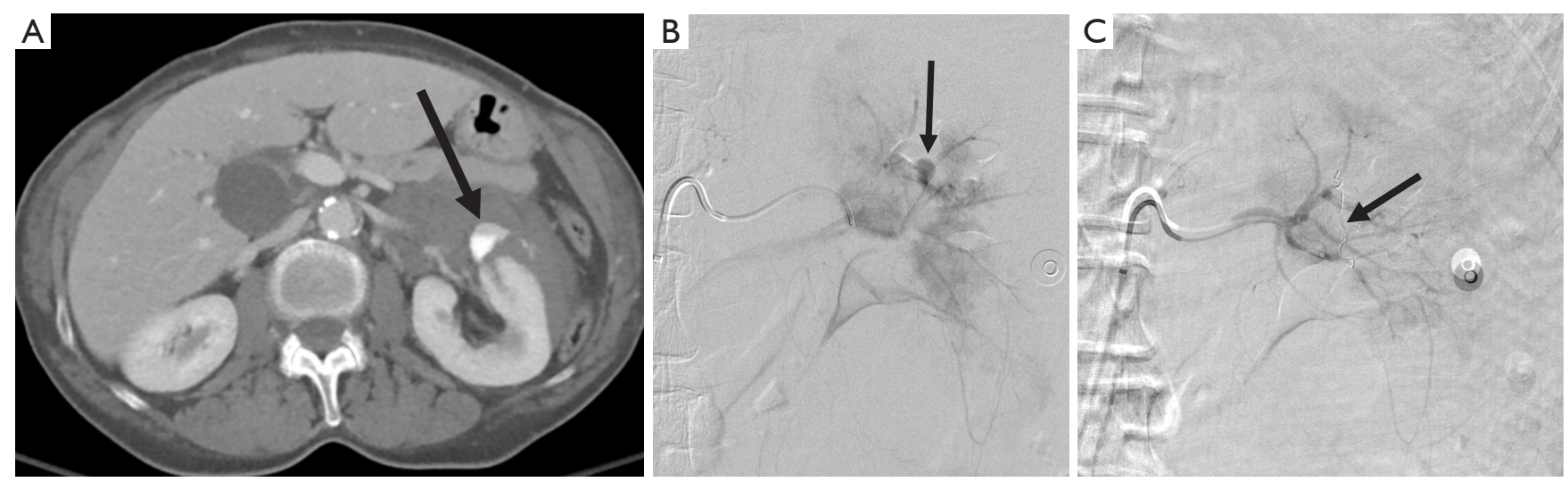

Figure 1 A 62-year-old female who was the driver of a pickup truck, which was struck by a train. Routine trauma CT was performed (A), and demonstrated a left kidney laceration with active extravasation of contrast (black arrow). The patient was taken to angiography (B), which demonstrated active extravasation (black arrow). Super-selective coil embolization (black arrow) was performed, which led to devascularization of the extravasating artery $(\mathrm{C})$.
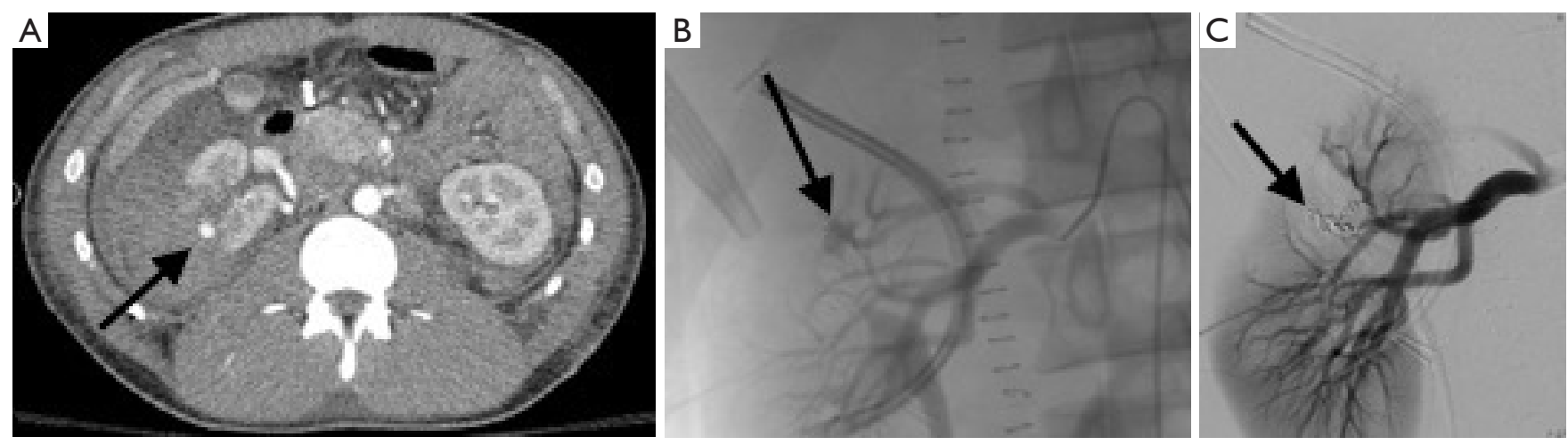

Figure 2 A 55-year-old male in a motor vehicle collision. Routine trauma scan demonstrated active extravasation of contrast from the right kidney (black arrow), consistent with renal artery injury (A). The patient was taken to angiography, which demonstrated active extravasation of contrast (black arrow) from an interlobar artery (B). Selective coil embolization was performed (black arrow) and final angiogram demonstrated cessation of contrast extravasation (C).

with selective embolization (Figures 1,2) (15-17). Vascular avulsion requires surgical treatment, including attempted revascularization if within the timeline for salvage of viable tissue $(6,11)$. Patients can have preserved blood pressure despite significant blood loss when a perinephric hematoma causes Page kidney, wherein compression of segmental and subsegmental blood vessels leads to the activation of the renin-angiotensin system (Figure 3) (18).

\section{Endovascular embolization technique}

Aortogram, which can be done to evaluate the origin of renal arteries and the presence of accessory renal arteries, can be avoided if CT has been performed immediately prior. Transfemoral access is generally preferred. After placing a vascular sheath in the common femoral arteries, the renal artery is selected using a curved catheter, such as a Cobra-2, or a reverse-curve catheter, such as a SOS Omni Selective Catheter or Simmons (19). If a trans-radial approach is taken, a Judkins Right 5 (JR5) can be used (20). Selective angiography of the renal arteries is performed with an injection rate of $5-6 \mathrm{~mL} / \mathrm{s}$ for $2-3$ seconds (19). Microcatheter and microwires are then used to subselect the injured segmental or subsegmental artery; selective embolization is preferred, when possible, to preserve renal function as renal function can even be preserved 

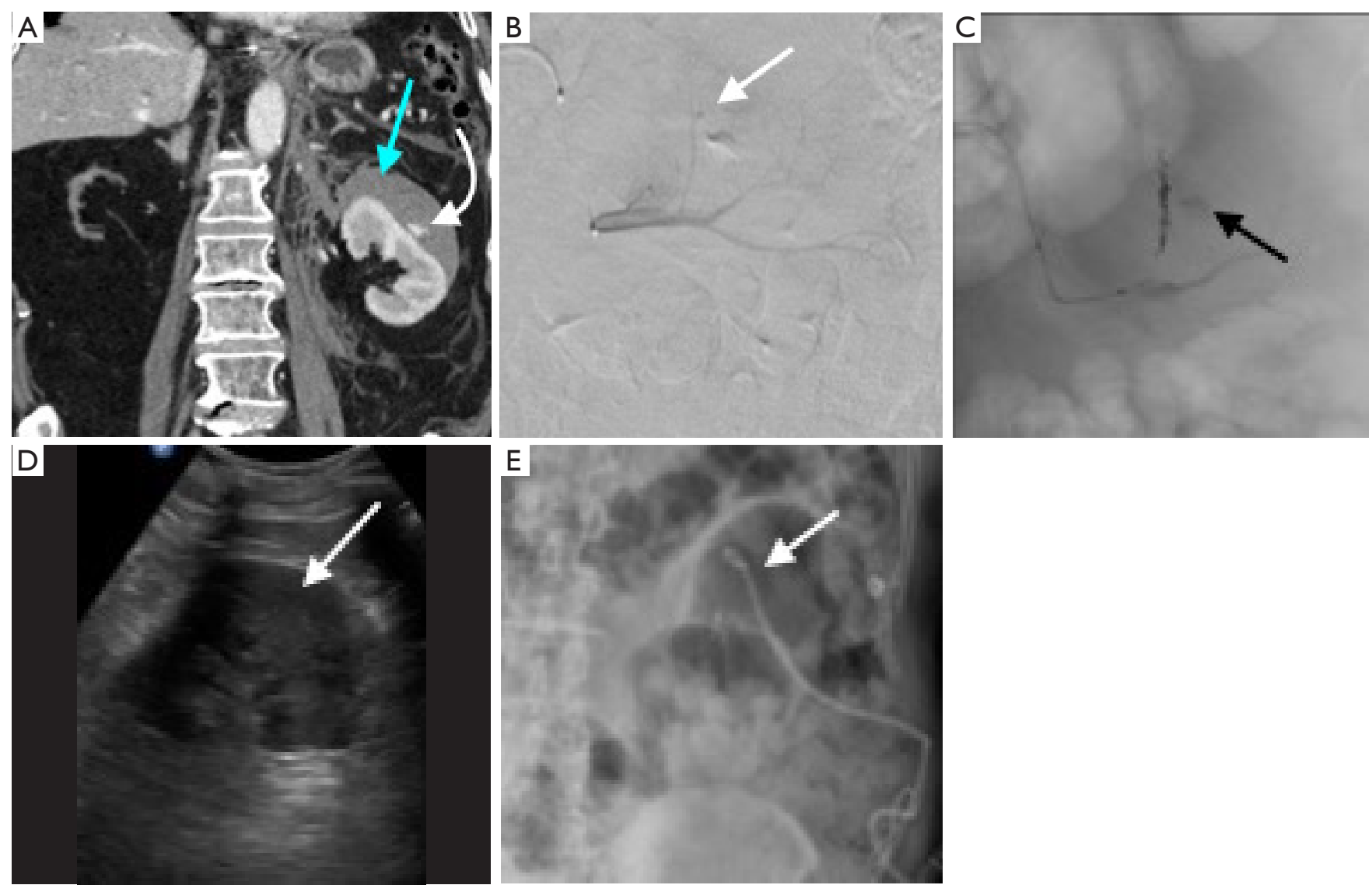

Figure 3 A 92-year-old male with a functionally solitary left kidney who presented to the emergency department after an unwitnessed ground-level fall. In the emergency department, his creatinine was $3.2 \mathrm{mg} / \mathrm{dL}$, up from a baseline of $1.6 \mathrm{mg} / \mathrm{dL}$, and his blood pressure was 212/122 mmHg. (A) CT scan of the abdomen and pelvis demonstrated a subcapsular hematoma compressing the kidney (blue arrow) with active extravasation of contrast (curved white arrow). (B) Selective angiography of the kidney demonstrated a focal pseudoaneurysm arising from an interlobar artery (white arrow). Super-selective coil embolization was performed. (C) Repeat angiography demonstrated pooling of contrast adjacent to the coiled pseudoaneurysm (black arrow) and complete devascularization of the affected interlobar artery. Given the clinical presentation of a Page kidney, attention was then turned to draining the subcapsular hematoma. (D) Ultrasound images demonstrated a subcapsular hematoma compressing the renal parenchyma (white arrow). An 8.2-French multipurpose drain was placed in the subcapsular hematoma. (E) Post-procedure abdominal radiograph demonstrates coils within the kidney and a well-positioned pigtail drain superior to the renal parenchyma (white arrow).

in patients with grade IV lacerations $(4,6)$. In cases of a shattered kidney without renal hilum avulsion, a proximal embolization of the main renal artery can be used as a non-surgical alternative to nephrectomy (Figure 4) (6,21-24). In cases of complete vascular pedicle avulsion, embolization is contraindicated and the patient should be managed operatively $(25,26)$. Embolization is most often performed with gelfoam and/or coils. Gelfoam and other particles should be avoided when there is an arterio-venous fistula present due to risk of pulmonary embolism (Figure 5). If no vascular injury can be identified at angiography
(Figure 6) embolization should not be performed (6). Trauma to the main renal artery that requires revascularization, such as dissection or occlusion, can be treated with percutaneous procedures using stents (27). Ideal patients for this type of intervention are hemodynamically stable with an ischemic kidney time of under 3 hours $(3,6,28,29)$.

\section{Outcomes}

When arterial injury is identified by angiography and technically successful embolization is performed, reported 

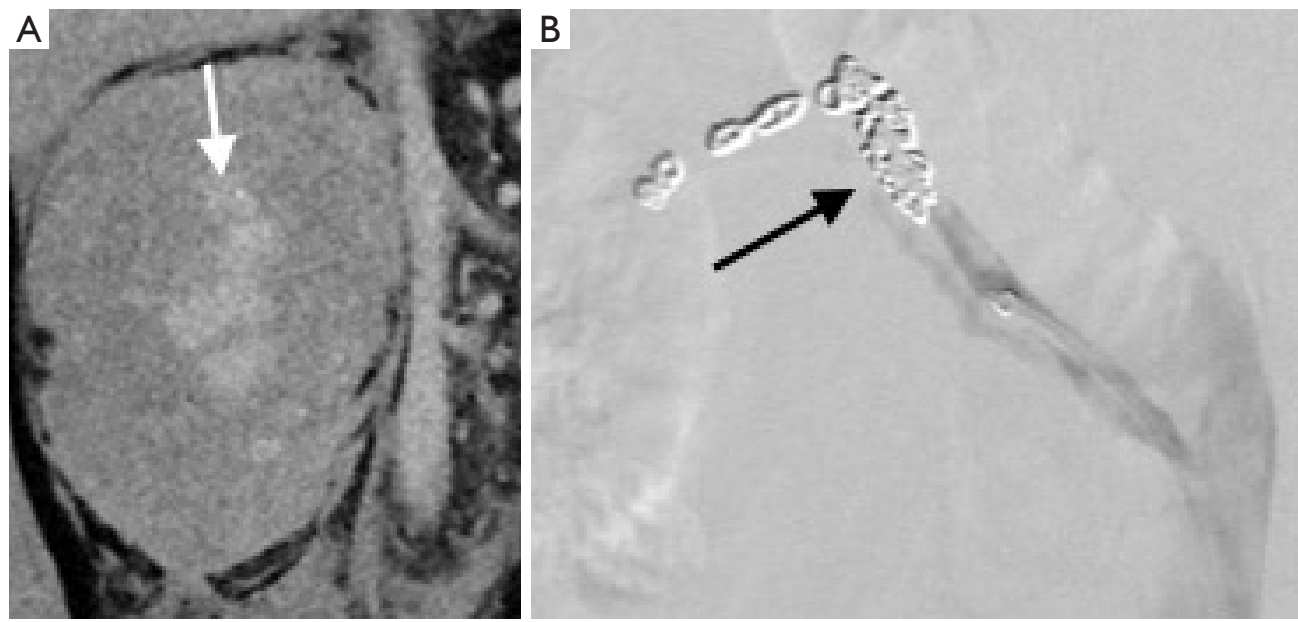

Figure 4 A 64-year-old male involved in a high-speed motor vehicle collision. Contrast-enhanced coronal CT (A) demonstrated a shattered kidney (white arrow) and a main renal artery vascular injury (not shown). The patient was taken to angiography (B) and the proximal main renal artery was embolized with coils (black arrow).
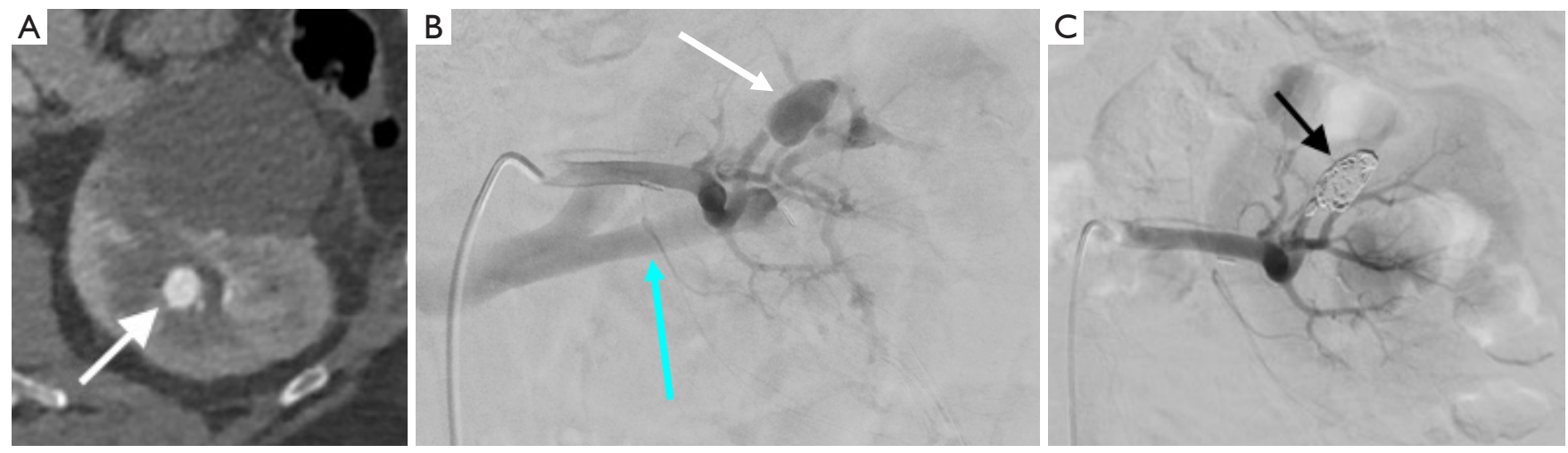

Figure 5 A 56-year-old male with a history of clear cell RCC who was 1 day post-partial nephrectomy who presented with gross hematuria. Contrast enhanced CT (A) demonstrated a pseudoaneurysm near the nephrectomy margin (white arrow). (B) Angiogram demonstrated combined pseudoaneurysm (white arrow) and arteriovenous fistula confirmed by early filling of the main renal vein (blue arrow). (C) The patient was treated with coils only (black arrow), as particle embolization is contraindicated in cases of arteriovenous fistula. RCC, renal cell carcinoma; CT, computed tomography.

success rates of non-operative management ranges from $63-100 \%$, with the vast majority of clinical failure following embolization observed in AAST grade $\mathrm{V}$ renal injury $(6,15,30-35)$. One study showed a low initial rate of embolization success (63\%), but when repeat embolization was performed the clinical success rate increased to $95 \%$ (33). That study reported markedly different results when compared to others which showed between 94.4-100\% initial clinical success rates of non-operative management for stable patients with AAST grade IV and V renal injuries when triaged to embolization (32,34-38).

Pediatric patients with blunt abdominal trauma and evidence of vascular injury on CT have a very high success rate when treated with angiography and embolization (reported up to 100\%) and a low morbidity rate (39-41). Given these success rates, angiography and selective angioembolization is considered a first line treatment; hemodynamically borderline pediatric patients can be treated with embolization when appropriate surgical backup is available (6,39-41). 

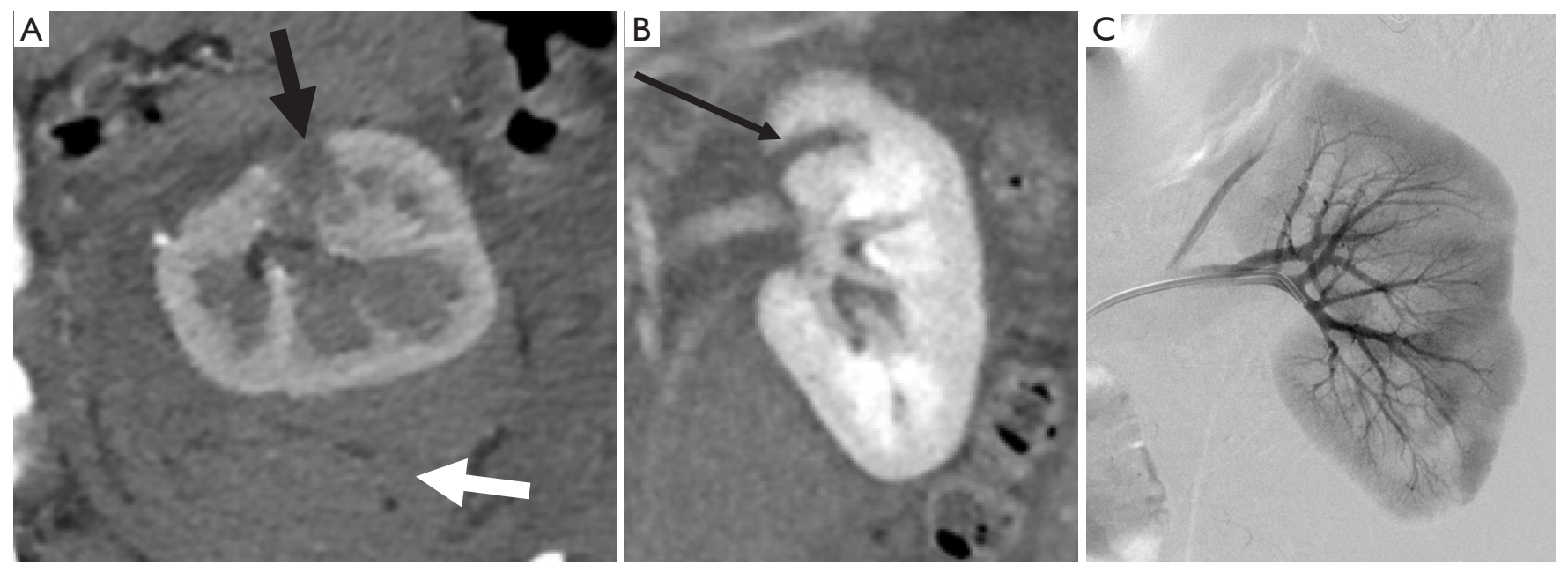

Figure 6 A 17-year-old male with left flank pain following a motor vehicle collision. Axial (A) and coronal (B) CT of the abdomen and pelvis with a left renal laceration measuring approximately $1.5 \mathrm{~cm}$ (black arrows), and an adjacent perinephric hematoma (white arrow), consistent with a AAST grade III renal injury (A,B). The patient was taken to angiography; however, no focal extravasation or vascular injury was appreciated (C) and no embolization was performed. Despite the CT findings, up to $32 \%$ of blunt renal trauma with evidence of extravasation on CT imaging are negative at the time of angiogram. CT, computed tomography; AAST, the American Association for the Surgery of Trauma.

\section{Complications}

Renal embolization can lead to short-term hypertension due to activation of the renin-angiotensin system, and may persist if embolization results in significant ischemia (42). Decrease in renal function can be caused by a variety of factors including contrast-induced nephropathy, especially in those with pre-existing renal insufficiency, older patients and those with diabetes, parenchymal tissue loss from the trauma, and non-selective embolization (43). While current Society of Interventional Radiology (SIR) guidelines do not include a recommendation for antibiotics prior to renal embolization, infection can occur if there is a large perinephric hematoma (Figure 7) or if non-selective embolization is performed (44). Cefazolin has been shown to reduce the risk of infection and should be considered in these scenarios $(44,45)$.

\section{Discussion and summary}

Renal trauma is most commonly seen in the setting of blunt abdominal injury but can also be seen with penetrating injury, which is often iatrogenic in etiology. Hemodynamically stable patients with significant blunt or penetrating trauma should be evaluated with contrastenhanced CT. If renal injury is suspected based on mechanism, hematuria or abnormality seen on initial images, a delayed excretory phase CT should be obtained to evaluate for urinary collecting system injury (7). Observation should be the treatment of choice for all hemodynamically stable or stabilized minor (AAST III) renal injury when no vascular contrast extravasation is seen. Hemodynamically stable patients with moderate (AAST III) and severe (AAST IV-V) injuries, when there is no other indication for surgery, should be managed with selective embolization, which is safe and highly effective (6). Hemodynamically unstable patients with high grade injury should undergo emergent nephrectomy (6). Embolization is typically performed with coils and/or gelfoam. Proximal or main renal artery injury can be treated with stent and/or stent graft in selected cases. Endovascular embolization has few large prospective trials, and thus this review is limited by the lack of current evidence. Smaller retrospective trials are promising, however larger prospective trials are needed to further refine indications and expected outcomes for the endovascular treatment of renal trauma. Further trials are also needed to investigate the best practices for antibiotic use in the setting of renal embolization. 

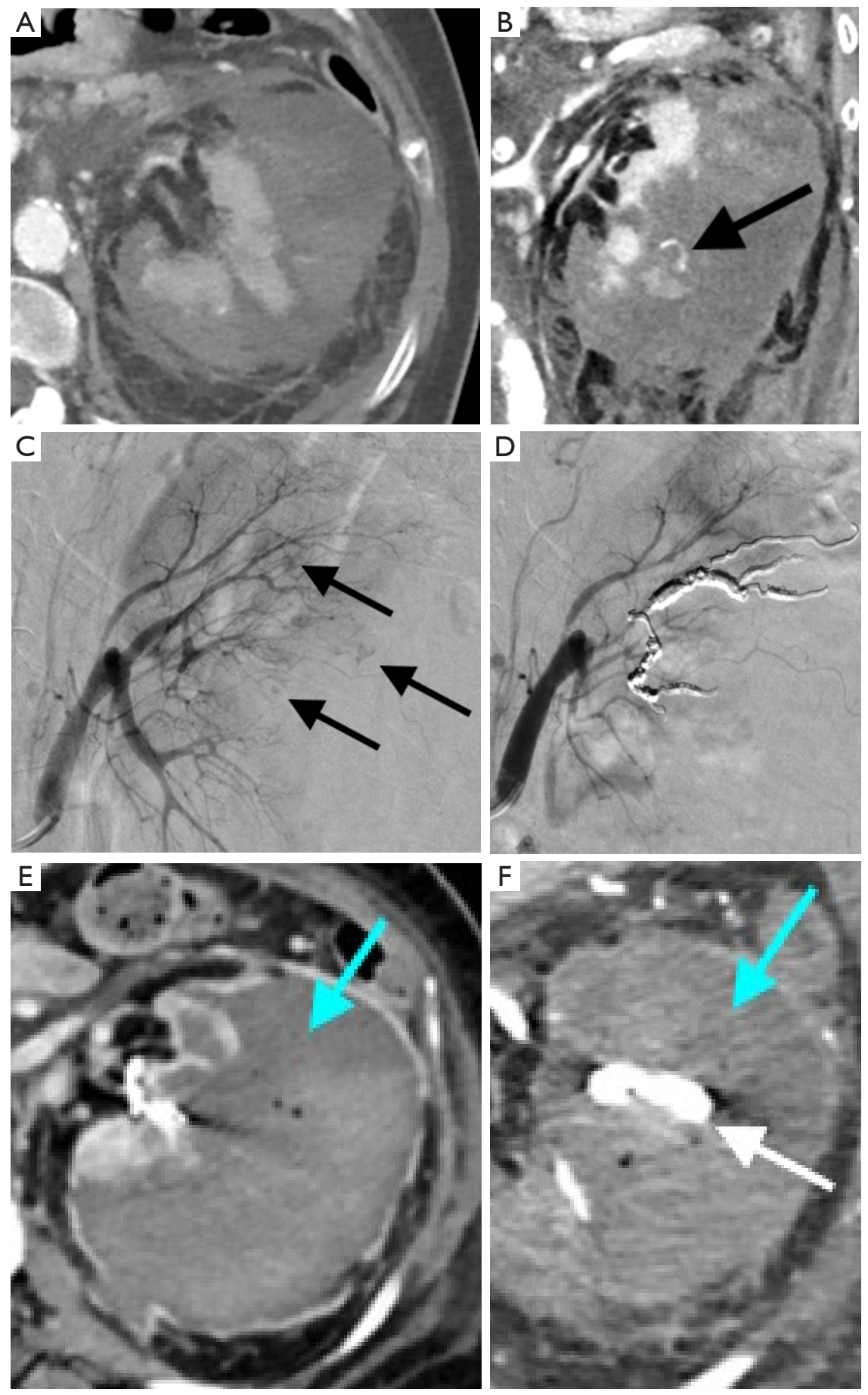

Figure 7 A 65-year-old female who presented following a high-speed motor vehicle collision. Contrast-enhanced CT scan demonstrated multiple deep lacerations extending to the renal collecting system with areas of active extravasation (black arrow) and a large hematoma, consistent with AAST grade IV injury (A, axial; B, coronal). Patient was deemed to be not a surgical candidate and therefore emergent embolization was performed. Angiography (C) demonstrated multifocal contrast extravasation (black arrows). Multiple selective coils were placed, and post-embolization angiography demonstrated resolution of contrast extravasation (D). Post-procedure course was complicated by an infected perinephric hematoma (blue arrows), which required drain placement (white arrow) (E,F). CT, computed tomography; AAST, the American Association for the Surgery of Trauma. 


\section{Acknowledgments}

Funding: None.

\section{Footnote}

Provenance and Peer Review: This article was commissioned by the Guest Editor (Dr. Keith Bertram Quencer) for the series "Endovascular interventions in trauma" published in Annals of Translational Medicine. The article was sent for external peer review organized by the Guest Editor and the editorial office.

Reporting Checklist: The authors have completed the Narrative Review reporting checklist. Available at http:// dx.doi.org/10.21037/atm-20-4310

Conflicts of Interest: All authors have completed the ICMJE uniform disclosure form (available at http://dx.doi. org/10.21037/atm-20-4310). The series "Endovascular interventions in trauma" was commissioned by the editorial office without any funding or sponsorship. KBQ served as the unpaid Guest Editor of the series and serves as an unpaid editorial board member of Annals of Translational Medicine from Aug 2019 to Jul 2021. The authors have no other conflicts of interest to declare.

Ethical Statement: The authors are accountable for all aspects of the work in ensuring that questions related to the accuracy or integrity of any part of the work are appropriately investigated and resolved.

Open Access Statement: This is an Open Access article distributed in accordance with the Creative Commons Attribution-NonCommercial-NoDerivs 4.0 International License (CC BY-NC-ND 4.0), which permits the noncommercial replication and distribution of the article with the strict proviso that no changes or edits are made and the original work is properly cited (including links to both the formal publication through the relevant DOI and the license). See: https://creativecommons.org/licenses/by-ncnd $/ 4.0 /$.

\section{References}

1. Kodama R. Contemporary treatment of renal trauma in Canada. Can Urol Assoc J 2019;13:S46-50.

2. Petrone P, Perez-Calvo J, Brathwaite CEM, et al.
Traumatic kidney injuries: A systematic review and metaanalysis. Int J Surg 2020;74:13-21.

3. Sauk S, Zuckerman DA. Renal artery embolization. Semin Intervent Radiol 2011;28:396-406.

4. Titton RL, Gervais DA, Boland GW, et al. Renal Trauma: Radiologic Evaluation and Percutaneous Treatment of Nonvascular Injuries. AJR Am J Roentgenol 2002;178:1507-11.

5. Martin JG, Shah J, Robinson C, et al. Evaluation and Management of Blunt Solid Organ Trauma. Tech Vasc Interv Radiol 2017;20:230-6.

6. Coccolini F, Moore EE, Kluger Y, et al. Kidney and urotrauma: WSES-AAST guidelines. World J Emerg Surg 2019; $14: 54$.

7. Smith JK, Kenney PJ. Imaging of renal trauma. Radiol Clin North Am 2003;41:1019-35.

8. Mani NB, Kim L. The Role of Interventional Radiology in Urologic Tract Trauma. Semin Intervent Radiol 2011;28:415-23.

9. Dane B, Baxter AB, Bernstein MP. Imaging Genitourinary Trauma. Radiol Clin North Am 2017;55:321-35.

10. Heller MT, Schnor N. MDCT of renal trauma: correlation to AAST organ injury scale. Clin Imaging 2014;38:410-7.

11. Moore EE, Shackford SR, Pachter HL, et al. Organ injury scaling: spleen, liver, and kidney. J Trauma 1989;29:1664-6.

12. Mansbridge MM, Ryan J, Hill DC, et al. Renal trauma: a 3year audit from a Gold Coast trauma centre. ANZ J Surg 2019;89:339-44.

13. Kautza B, Zuckerbraun B, Peitzman AB. "Management of blunt renal injury: what is new?" Eur J Trauma Emerg Surg 2015;41:251-8.

14. Bartley JM, Santucci RA. Computed tomography findings in patients with pediatric blunt renal trauma in whom expectant (nonoperative) management failed. Urology 2012;80:1338-43.

15. Breyer BN, McAninch JW, Elliott SP, et al. Minimally Invasive Endovascular Techniques to Treat Acute Renal Hemorrhage. J Urol 2008;179:2248-52; discussion 2253.

16. Antunes-Lopes T, Pinto R, Morgado P, et al. Intrarenal artery pseudoaneurysm after blunt abdominal trauma: a case report of successful superselective angioembolization. Res Rep Urol 2014;6:17-20.

17. Fu CY, Wu SC, Chen RJ, et al. Evaluation of need for operative intervention in blunt splenic injury: Intraperitoneal contrast extravasation has an increased probability of requiring operative intervention. World J Surg 2010;34:2745-51. 
18. Haydar A, Bakri RS, Prime M, et al. Page kidney - A review of the literature. J Nephrol 2003;16:329-33.

19. Kaufman JA, Lee MJ. Vascular and Interventional Radiology: The Requisites. 2nd edition. Philadelpha: Elsevier, 2014.

20. Ruzsa Z, Tóth K, Jambrik Z, et al. Transradial access for renal artery intervention. Interv Med Appl Sci 2014;6:97-103.

21. Lanchon C, Fiard G, Arnoux V, et al. High Grade Blunt Renal Trauma: Predictors of Surgery and Long-Term Outcomes of Conservative Management. A Prospective Single Center Study. J Urol 2016;195:106-11.

22. Hotaling JM, Sorensen MD, Smith TG, et al. Analysis of Diagnostic Angiography and Angioembolization in the Acute Management of Renal Trauma Using a National Data Set. J Urol 2011;185:1316-20.

23. Stewart AF, Brewer ME, Daley BJ, et al. IntermediateTerm Follow-Up of Patients Treated With Percutaneous Embolization for Grade 5 Blunt Renal Trauma. J Trauma 2010;69:468-70.

24. Brewer ME, Strnad BT, Daley BJ, et al. Percutaneous Embolization for the Management of Grade 5 Renal Trauma in Hemodynamically Unstable Patients: Initial Experience. J Urol 2009;181:1737-41.

25. Hagiwara A, Sakaki S, Goto H, et al. The Role of Interventional Radiology in the Management of Blunt Renal Injury: A Practical Protocol. J Trauma 2001;51:526-31.

26. Charbit J, Manzanera J, Millet I, et al. What are the specific computed tomography scan criteria that can predict or exclude the need for renal angioembolization after high-grade renal trauma in a conservative management strategy? J Trauma 2011;70:1219-27; discussion 1227-8.

27. Lee JT, White RA. Endovascular management of blunt traumatic renal artery dissection. J Endovasc Ther 2002;9:354-8.

28. Tennankore KK, Kim SJ, Alwayn IPJ, et al. Prolonged warm ischemia time is associated with graft failure and mortality after kidney transplantation. Kidney Int 2016;89:648-58.

29. Heylen L, Pirenne J, Samuel U, et al. The Impact of Anastomosis Time During Kidney Transplantation on Graft Loss: A Eurotransplant Cohort Study. Am J Transplant 2017;17:724-32.

30. Sarani B, Powell E, Taddeo J, et al. Contemporary Comparison of Surgical and Interventional Arteriography Management of Blunt Renal Injury. J Vasc Interv Radiol
2011;22:723-8.

31. Muller A, Rouvière O. Renal artery embolizationindications, technical approaches and outcomes. Nat Rev Nephrol 2015;11:288-301.

32. Shoobridge JJ, Bultitude MF, Koukounaras J, et al. A 9-year experience of renal injury at an Australian level 1 trauma centre. BJU Int 2013;112:53-60.

33. Huber J, Pahernik S, Hallscheidt P, et al. Selective Transarterial Embolization for Posttraumatic Renal Hemorrhage: A Second Try is Worthwhile. J Urol 2011;185:1751-5.

34. Sugihara T, Yasunaga H, Horiguchi H, et al. Management trends, angioembolization performance and multiorgan injury indicators of renal trauma from Japanese administrative claims database. Int J Urol 2012;19:559-63.

35. Aragona F, Pepe $P$, Patanè D, et al. Management of severe blunt renal trauma in adult patients: a 10-year retrospective review from an emergency hospital. BJU Int 2012;110:744-8.

36. Morita S, Inokuchi S, Tsuji T, et al. Arterial embolization in patients with grade-4 blunt renal trauma: evaluation of the glomerular filtration rates by dynamic scintigraphy with 99m Technetium-diethylene triamine pentacetic acid. Scand J Trauma Resusc Emerg Med 2010;18:11.

37. Chow SJD, Thompson KJ, Hartman JF, et al. A 10-year review of blunt renal artery injuries at an urban level I trauma centre. Injury 2009;40:844-50.

38. Yanagi M, Suzuki Y, Hamasaki T, et al. Early Transcatheter Arterial Embolization for the American Association for the Surgery of Trauma Grade 4 Blunt Renal Trauma in Two Institutions. J Nippon Med Sch 2018;85:204-7.

39. Kiankhooy A, Sartorelli KH, Vane DW, et al. Angiographic Embolization Is Safe and Effective Therapy for Blunt Abdominal Solid Organ Injury in Children. J Trauma 2010;68:526-31.

40. Lin WC, Lin CH. The role of interventional radiology for pediatric blunt renal trauma. Ital J Pediatr 2015;41:76.

41. Eassa W, El-Ghar MA, Jednak R, et al. Nonoperative Management of Grade 5 Renal Injury in Children: Does It Have a Place? Eur Urol 2010;57:154-61.

42. Loffroy R, Chevallier O, Gehin S, et al. Endovascular management of arterial injuries after blunt or iatrogenic renal trauma. Quant Imaging Med Surg 2017;7:434-42.

43. Ierardi AM, Duka E, Lucchina N, et al. The role of interventional radiology in abdominopelvic trauma. Br J Radiol 2016;89:20150866.

44. Loffroy R, Rao P, Kwak BK, et al. Transcatheter Arterial Embolization in Patients with Kidney Diseases: 
Page 12 of 12

an Overview of the Technical Aspects and Clinical Indications. Korean J Radiol 2010;11:257.

45. Stawicki SP. Trends in nonoperative management of

Cite this article as: Smith TA, Eastaway A, Hartt D, Quencer KB.

Endovascular embolization in renal trauma: a narrative review. Ann Transl Med 2021;9(14):1198. doi: 10.21037/atm-20-4310
Smith et al. Renal trauma and the role of endovascular therapy

traumatic injuries - A synopsis. Int J Crit Illn Inj Sci 2017;7:38. 